\title{
A six week double blind, placebo controlled, crossover study of the effect of misoprostol in the treatment of aspirin sensitive asthma
}

\author{
Wojciech Wasiak, Mirosław Szmidt
}

\begin{abstract}
Background-Prostaglandins of the $E$ series and misoprostol (a stable analogue of prostaglandin $\mathrm{E}_{1}$ ) prevent bronchoconstriction following aspirin ingestion or inhalation in subjects with aspirin sensitive asthma. A study was undertaken to investigate the influence of misoprostol on the course of aspirin induced asthma.

Methods-A double blind, crossover, randomised, placebo controlled study was performed in 17 patients with aspirin sensitive asthma (13 women) aged 26-68 years. All subjects had aspirin sensitivity confirmed by means of oral aspirin or inhaled lysine aspirin challenge. Misoprostol (Cytotec, Searle, 800 or $1600 \mu \mathrm{g}$ daily according to individual tolerance) or placebo were administered over a period of six weeks. Morning and evening peak expiratory flow rate (PEFR), $\beta_{2}$ agonist use, asthma and rhinitis severity scores, and defaecation score were measured daily. At the beginning and end of each treatment period spirometric tests were performed and blood was taken for eosinophil count. Eight subjects took misoprostol at a dose of $800 \mu \mathrm{g}$ and nine subjects at a dose of $1600 \mu \mathrm{g}$ daily.

Results-No differences were seen in asthma control between misoprostol and placebo except for the rhinorrhoea score which was lower on misoprostol during the period of the study.

Conclusion-Misoprostol in a daily dose of 800 or $1600 \mu \mathrm{g}$ does not significantly improve asthma control in subjects with aspirin sensitive asthma.

(Thorax 1999;54:900-904)
\end{abstract}

IInd Department of

Keywords: aspirin sensitive asthma; prostaglandin $\mathrm{E}_{1}$; misoprostol

Tuberculosis and Lung

Diseases, Institute of

Tuberculosis and Lung

Disease in Warsaw, 181

Okólna Str., 91-520

Lódź, Poland

W Wasiak

M Szmidt

Correspondence to:

Dr M Szmidt.

Received 28 September 1998 Returned to authors

11 February 1999

Revised manuscript received

2 June 1999

Accepted for publication

23 June 1999 (IL) -1, IL-2, tumour necrosis factor (TNF)- $\alpha$, and interferon (IFN) $-\gamma .^{78}$ The synthesis and release of leukotrienes is also likely to be downregulated by PGE. ${ }^{139}$ Misoprostol, a stable analogue of $\mathrm{PGE}_{1}$, inhibits prolongation of eosinophil survival by IL-3 and IL-5, platelet aggregating factor (PAF) induced and $\mathrm{C} 5 \mathrm{a}$ induced eosinophil chemotaxis, production of granulocyte-macrophage colony stimulating factor (GM-CSF) by lymphocytes, and inhibits the cutaneous late allergic reaction measured by the number of infiltrating cells. ${ }^{10}$ Liposome associated $\mathrm{PGE}_{1}$ inhibits acute inflammation in animal models, even when applied two hours after initiating the processes of inflammation. ${ }^{11}$

$\mathrm{PGE}_{2}$, which is normally present in the bronchial mucosa at concentrations some 10-50 times higher than that of other AA metabolites, might be a powerful local protective factor, preventing bronchoconstriction in response to numerous stimuli and helping to maintain homeostasis. ${ }^{12}$ We hypothesised that altered $\mathrm{PGE}_{2}$ production might be involved in the pathogenesis of aspirin induced asthma. ${ }^{13}$ Inhaled $\mathrm{PGE}_{2}$, although a weak bronchodilator, prevents bronchoconstriction following inhalation of allergen, ${ }^{14}$ nebulised distilled water, ${ }^{15}$ and sodium metabisulphite, ${ }^{16}$ and after physical exertion. ${ }^{17}$ Oral misoprostol, intravenous $\mathrm{PGE}_{1}$, and inhaled $\mathrm{PGE}_{2}$ have inhibited or completely abolished aspirin induced bronchoconstriction in aspirin sensitive asthmatic subjects in several studies. ${ }^{18-21}$

Misoprostol can prevent and heal gastrointestinal ulcerations induced by non-steroidal anti-inflammatory drugs. ${ }^{22}$ It has been reported to have a similar effect to natural PGE on immunological processes. ${ }^{2} 78192324$ The purpose of the present study was to investigate the effect of regular administration of misoprostol on the course of aspirin sensitive asthma.

\section{Methods}

Seventeen patients (13 women) were included in the study and in all cases asthma was diagnosed according to the criteria used in the Global Initiative for Asthma Management and Prevention. ${ }^{25}$ Aspirin intolerance, suggested by a history of bronchospasm after aspirin ingestion, was confirmed by means of inhaled lysine aspirin $^{26}$ or oral aspirin challenge ${ }^{27}$ as described below. Patients who suffered from any clinically significant pulmonary, heart, renal or liver disorder and women of childbearing potential not using adequate contraception were excluded. The baseline forced expiratory volume in one second $\left(\mathrm{FEV}_{1}\right)$ was 83 (15)\% predicted and patients responded with more than a $15 \%$ increase following inhalation of $1 \mathrm{mg}$ terbutaline (Bricanyl Turbuhaler, Astra, Sweden) on at least one occasion during the six months

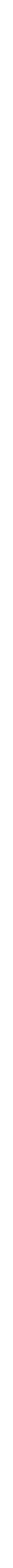


Table 1 Characteristics of patients in the study

\begin{tabular}{|c|c|c|c|c|c|c|c|c|c|c|}
\hline Patient no. & Sex & $\begin{array}{l}\text { Age } \\
\text { (years) }\end{array}$ & Atopy & $\begin{array}{l}\text { Nasal } \\
\text { polyps }\end{array}$ & $\begin{array}{l}\text { Asthma } \\
\text { duration } \\
\text { (years) }\end{array}$ & $\begin{array}{l}\text { Aspirin } \\
\text { intolerance } \\
\text { duration } \\
\text { (years) }\end{array}$ & $\begin{array}{l}\text { Oral aspirin } \\
\text { threshold } \\
\text { dose (mg) }\end{array}$ & $\begin{array}{l}\text { Inhaled lysine } \\
\text { aspirin } \\
\text { threshold } \\
\text { concentration } \\
\text { (mg/ml) }\end{array}$ & Treatment & $\begin{array}{l}\text { Asthma } \\
\text { severity grade } \\
\text { (GINA) }\end{array}$ \\
\hline 1 & $\mathrm{~F}$ & 50 & Yes & Yes & 12 & 3 & 20 & & ICS, STP & 4 \\
\hline 2 & $\mathrm{~F}$ & 48 & Yes & No & 15 & 11 & & 180 & ICS, STP & 2 \\
\hline 3 & $\mathrm{~F}$ & 48 & Yes & Yes & 1 & 1 & & 45 & STP & 2 \\
\hline 4 & M & 48 & Yes & Yes & 2 & 2 & & 90 & ICS, NCS, STP & 3 \\
\hline 5 & $\mathrm{M}$ & 26 & Yes & Yes & 9 & 7 & 150 & & ICS, NCS, DSCG, STP, LAB & 2 \\
\hline 6 & $\mathrm{~F}$ & 64 & Yes & Yes & 21 & 21 & 100 & & ICS, STP & 2 \\
\hline 7 & $\mathrm{~F}$ & 45 & Yes & Yes & 15 & 14 & 80 & & ICS, & 2 \\
\hline 8 & $\mathrm{~F}$ & 59 & Yes & Yes & 21 & 15 & 150 & & ICS, STP & 2 \\
\hline 9 & $\mathrm{~F}$ & 33 & Yes & Yes & 11 & 11 & 10 & & ICS, & 3 \\
\hline 10 & $\mathrm{~F}$ & 57 & Yes & No & 32 & 27 & 30 & & STP & 3 \\
\hline 11 & $\mathrm{~F}$ & 68 & No & No & 1 & 1 & & 22.5 & ICS, STP & 3 \\
\hline 12 & $\mathrm{~F}$ & 51 & Yes & No & 8 & 4 & 60 & & ICS, OCS, STP, NS, KET & 4 \\
\hline 13 & $\mathrm{M}$ & 48 & Yes & No & 16 & 11 & 80 & & ICS, NCS & 3 \\
\hline 14 & $\mathrm{~F}$ & 62 & No & No & 16 & 13 & 60 & & ICS, OCS, STP & 4 \\
\hline 15 & $\mathrm{~F}$ & 67 & No & Yes & 3 & 1 & & 180 & ICS, NCS, STP & 3 \\
\hline 16 & M & 43 & Yes & Yes & 4 & 2 & 40 & & ICS, STP, AST & 3 \\
\hline & $\mathrm{F}$ & 41 & Yes & No & 12 & 10 & 60 & & ICS, NCS, STP & 3 \\
\hline Mean (SD) & & $50.5(11.5)$ & & & $11.7(8.4)$ & $9.1(7.6)$ & & & & $2.82(0.73)$ \\
\hline
\end{tabular}

ICS $=$ inhaled corticosteroids OCS $=$ oral corticosteroids NCS $=$ nasal corticosteroids STP $=$ sustained release theophylline preparations; DCSG $=$ disodium cromoglycate; $\mathrm{NS}=$ nedocromil sodium $; \mathrm{KET}=$ ketotifen fumarate; $\mathrm{AST}=$ astemizol; $\mathrm{LAB}=$ long acting $\beta_{2}$ mimetic.

preceding the study. Fifteen subjects were on regular treatment with inhaled steroids and two with oral steroids. The characteristics of the patients are shown in table 1 .

Pulmonary function was measured using a spirometer (Vitalograph Ltd, Buckinghamshire, UK). Inhaled lysine aspirin challenge test was performed according to the method of Phillips et $a .^{26}$ At least seven days later a placebo test was performed, using the same number of normal saline inhalations as in the lysine aspirin challenge test. Patients responding to any concentration of lysine aspirin with a $20 \%$ decrease in $\mathrm{FEV}_{1}$ from the post-saline value were considered to be aspirin sensitive. Otherwise, an oral aspirin test was performed.

Oral aspirin provocation tests ${ }^{27}$ began between 08.00 and 10.00 hours. Before the test all bronchodilating drugs were withdrawn, as described above. Aspirin (acetylsalicylic acid, Polfa, Poland) was used in capsules containing $10,20,40,60,100,150,300$, and $600 \mathrm{mg}$. On each test day the first baseline $\mathrm{FEV}_{1}$ was measured. Thereafter, provided the $\mathrm{FEV}_{1}$ exceeded $70 \%$ of the predicted value, the lowest aspirin dose $(10 \mathrm{mg})$ was administered and $\mathrm{FEV}_{1}$ was measured every hour for six hours. Any nasal or ocular symptoms were also recorded. If the fall in $\mathrm{FEV}_{1}$ after any dose of oral aspirin at any time was greater than $20 \%$ of baseline, or was between $15 \%$ and $20 \%$ with concomitant nasal or ocular symptoms, the test was interrupted and two inhalations of terbutaline via Turbuhaler were given, or other treatment as needed. Patients were then considered to be aspirin sensitive. In the other cases the test was repeated at least seven days later with the next dose of aspirin. If patients did not respond to $600 \mathrm{mg}$ oral aspirin with a fall in $\mathrm{FEV}_{1}$ of $20 \%$ of baseline they were considered to be tolerant to aspirin and did not enter the study.

The protocol was approved by the local ethics committee and all patients gave informed consent before being enrolled into the study.

\section{STUDY DESIGN}

The study was a double blind, placebo controlled, randomised, crossover trial. Patients were supplied with peak flow meters (Clement Clarke, UK) for the purpose of measuring peak expiratory flow (PEF) at home during the study. After a two week run-in period subjects were randomised to receive misoprostol (Cytotec, Searle) $400 \mu \mathrm{g}$ four times daily or matching placebo for a period of six weeks. This relatively high dose was reached by a gradual increase in the number of $200 \mu \mathrm{g}$ tablets, from four to eight, over the first five days of each treatment period (first day: $1+1+1+1$ tablets; second day: $2+1+1+1$ tablets; third day: $2+2+1$ +1 tablets; fourth day: $2+2+2+1$ tablets; fifth day and thereafter: 2 tablets q.i.d.). The dose of placebo was increased in the same manner. Patients who did not tolerate a dose of $400 \mu \mathrm{g}$ four times daily due to gastrointestinal symptoms (increased number of daily defaecations, diarrhoea, abdominal pain producing remarkable discomfort and interfering with their normal activities) were allowed to receive the lower dose of $200 \mu \mathrm{g}$ four times daily, which was generally well tolerated. After six weeks the subjects stopped taking the trial drug for a three week washout period. They then crossed over to the other limb of the study for another six weeks.

Each treatment period was started and finished with a clinic visit when physical examination, spirometric tests, ECG recording, and peripheral blood collection for eosinophil count were performed and blood pressure measured. During each period of the study subject data were collected on diary cards, including morning and evening PEF, consumption of rescue medication (short acting $\beta_{2}$ agonist), and asthma severity score (dyspnoea, 0-3 points), both separately for daytime and night time, cough, expectoration, nasal congestion, rhinorrhoea ( $0-2$ points), and defaecation scores. The clinical symptoms were scored as follows:

Night time asthma score: $0=$ slept all night, no symptoms; 1 = one awakening due to 
dyspnoea, dyspnoea not too severe; 2 = several awakenings, didn't sleep for more than half of the night; 3 = didn't sleep all night, severe dyspnoea.

Daytime asthma score: $0=$ no symptoms at all; $1=$ mild and short lasting dyspnoea, well tolerated; 2 = moderate dyspnoea, interfering with normal activity; 3 = severe incapacitating dyspnoea.

Nasal congestion: $0=$ no nasal obstruction; 1 $=$ difficulties with breathing through nose; $2=$ can't breathe through nose at all.

Rhinorrhoea: $0=$ no running nose; $1=$ moderately running nose, well tolerated; $2=$ severe rhinorrhoea, often needs handkerchief.

Cough: $0=$ no cough; $1=$ moderate well tolerated cough; 2 = severe fatiguing cough.

Expectoration: $0=$ no expectoration; $1=$ small amount of sputum, especially after bronchodilator usage; 2 = large amounts of sputum, expectorated all day long.

Patients also recorded the amounts of other asthma drugs they were taking, although they were asked not to change concomitant treatment without advising the investigator. At each visit subjects were specially asked for any adverse events and health problems that may have occurred. All unusual signs and symptoms were recorded for further consideration. The safety of the treatment was evaluated by monitoring ECG and blood pressure at clinic visits.

ANALYSIS OF DATA

The primary outcome variables were morning PEFR for asthma and both rhinorrhoea and nasal congestion scores for rhinitis. For analysis of the results, data from patients' diary cards were averaged over consecutive seven day periods. The highest value of every three morning and evening PEFR measurements was used in the analysis. In addition, for each patient diurnal variability of PEFR was calculated according to the following formula:

PEFR variability $=2\left[\left(\mathrm{PEF}_{\text {evening }}-\mathrm{PEF}_{\text {morning }}\right) /\right.$ $\left.\left(\mathrm{PEF}_{\text {evening }}+\mathrm{PEF}_{\text {morning }}\right)\right] \times 100 \%$

Data from the weeks of misoprostol and placebo treatments and averaged data from the whole six weeks of the study were independently compared using the Student's paired $t$ test (PEFR) and Wilcoxon matched pairs test (spirometric data, eosinophil counts, PEFR variability, all symptom scores, $\beta_{2}$ agonist usage, and defaecation scores).

\section{Results}

Mean (SD) morning PEFR during the run in period (333 (129) $1 / \mathrm{min}$ at week 1 and 336 (130) $1 / \mathrm{min}$ at week 2) and symptom scores indicated that the patients' asthma was stable. Of the 17 subjects, 10 received misoprostol in a dose of $1600 \mu \mathrm{g}$ daily, seven in a dose of $800 \mu \mathrm{g}$ daily, 15 received placebo at a dose of eight tablets, and two at a dose of four tablets. During the misoprostol period nine patients complained of an increased number of apparently normal defaecations per day, one patient of diarrhoea, four of abdominal pain, five of flatulence, and three of belching. During the

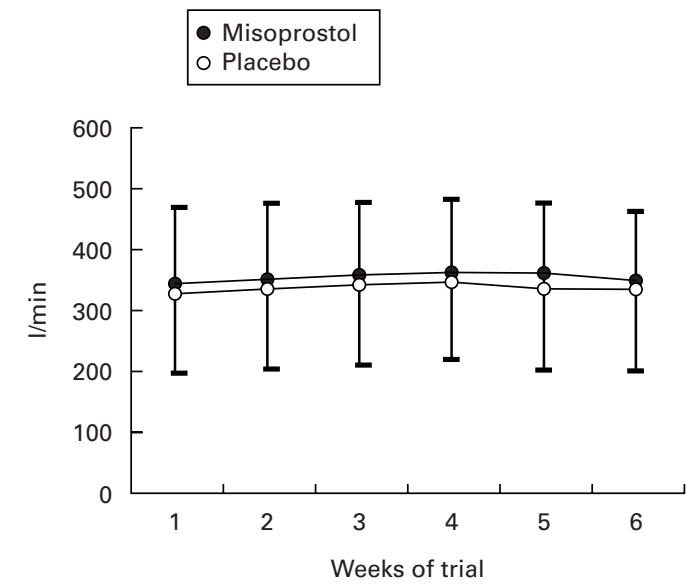

Figure 1 Mean (SD) morning PEFR in patients treated with misoprostol and those given placebo. Results are given as mean values, bars indicating $S D$.

placebo period three patients had an increased number of normal defaecations, one had abdominal pain, and one had nausea.

During both treatment periods four asthma exacerbations occurred (one on misoprostol and three on placebo, numbers too low to analyse), although they did not necessitate oral steroid treatment nor withdrawal from the study. There were no significant changes in ECG recordings or blood pressure.

None of the lung function parameters or eosinophil count before and after misoprostol treatment showed any significant differences.

There was no significant difference in morning PEFR over the study period between misoprostol (350 (120) $1 / \mathrm{min}$ ) and placebo (334 (128) $1 / \mathrm{min}, \mathrm{p}>0.05$; fig 1$)$. There were no differences in evening PEFR but diurnal variability in PEFR was slightly lower during the misoprostol period, although not reaching statistical significance. Consumption of rescue medication and asthma symptom scores showed no differences.

The rhinorrhoea score was significantly lower on misoprostol (median 0.36 points/day, range $0.00-2.00$ ) than on placebo (median 1.04 points/day, range 0.00-2.00) over the whole treatment period (mean difference 0.30 points/day, $95 \%$ CI 0.01 to $0.59 ; \mathrm{p}=0.031$ ). The defaecation score was higher on misoprostol (median 1.39/day, range $0.93-3.79$ ) than on placebo (median 1.10/day, range 0.55-2.02) during the whole treatment period (mean difference $0.65 /$ day, $95 \%$ CI 0.22 to $1.07 ; \mathrm{p}=$ 0.004 ) and in each separate week. None of the remaining parameters (cough, expectoration, and nasal congestion scores) changed significantly.

\section{Discussion}

Prostaglandins of the E series inhibit synthesis and release of many inflammatory mediators and cytokines and activation of some inflammatory cells. ${ }^{1-8}$ Increased leukotriene synthesis and release has been clearly demonstrated in aspirin sensitive asthmatic patients. ${ }^{28} 29$ It is likely that leukotriene production is controlled by $\mathrm{PGE}_{2}{ }^{1}{ }^{3}$

It has been postulated that inadequate $\mathrm{PGE}_{2}$ production may be a factor or cofactor in 
enhancing the acute aspirin intolerance reaction or being responsible for the permanent symptoms in subjects with aspirin sensitive asthma. Several studies have recently been undertaken to examine the effect of PGE on aspirin induced bronchoconstriction. Szczeklik et $a l^{19}$ and Sestini et $a l^{20}$ found that inhaled $\mathrm{PGE}_{2}$ diminished the bronchoconstrictor response to aspirin in aspirin sensitive asthmatic subjects. In our previous study ${ }^{18}$ and the study by Szczeklik et al ${ }^{19}$ misoprostol, a $\mathrm{PGE}_{1}$ stable analogue, caused the same effect, although its inhibitory potency was weaker than that of inhaled $\mathrm{PGE}_{2}$ and inhibition did not occur in every subject.

As $\mathrm{PGE}_{2}$ inhibits bronchoconstriction following exercise ${ }^{17}$ and allergen inhalation, ${ }^{14}$ it is not known whether the mechanism of PGE protection against aspirin is specific for this reaction. Direct proof of interference with the basal phenomenon of aspirin intolerance was provided by Sestini et $a l^{20}$ who reported an inhibition of the rise in the urine concentration of LTE4 by $\mathrm{PGE}_{2}$. Taniguchi et al showed that intravenous $\mathrm{PGE}_{1}$ caused no protection against allergen under the same conditions as it did against aspirin. ${ }^{21}$ Nevertheless, the most convincing explanation for its protective effect was inhibition of mast cell and/or eosinophil activation. It is unlikely that the protective effect of misoprostol against aspirin induced bronchoconstriction is due to a direct action on smooth muscle cells as natural $\mathrm{PGE}_{2}$ and misoprostol are relatively weak and short acting bronchodilators. ${ }^{1416}$

Considering the anti-inflammatory properties of PGE and its anti-eosinophilic effect in particular, some beneficial effects of prolonged treatment with a stable oral $\mathrm{PGE}_{1}$ analogue in aspirin induced asthma might be anticipated.

The overall effect of misoprostol in humans is harder to predict and interpret than that of natural $\mathrm{PGE}_{1}$ or $\mathrm{PGE}_{2}$. Misoprostol is an agonist of two of the four known PGE receptors (EP2 and EP3 receptors), the former causing an increase and the latter causing a decrease in intracellular cAMP. Nevertheless, in studies on some immunological activities misoprostol resembled natural $\mathrm{PGE}_{1}$ and $\mathrm{PGE}_{2}$ in their effects, with differences being small and only in potency. $^{278192324}$ Its pharmacokinetics and stability make misoprostol an adequate candidate for the study.

In our placebo controlled trial misoprostol given to aspirin sensitive asthmatic subjects in a dose of $800 \mu \mathrm{g}$ or $1600 \mu \mathrm{g}$ daily showed no significant effect on the course of the disease.

One of the possible explanations for the poor clinical effect of misoprostol in this study is that it did not reach a sufficiently high concentration in the bronchial mucosa. Misoprostol has an especially high affinity for the liver, kidney and gut compared with the bronchi. Nevertheless, its protective effect against oral aspirin over a similar dose range ${ }^{18}$ seems to exclude this hypothesis. Increased numbers of defaecations per day suggest that patients' compliance and drug intake were satisfactory. However, oral misoprostol at a single dose of $400 \mu \mathrm{g}$ showed somewhat poorer protection than inhaled $\mathrm{PGE}_{2}$ against aspirin provocation. ${ }^{19}$

Misoprostol given regularly to aspirin sensitive asthmatic patients showed a very poor effect on asthma control in this study. This does not exclude a role for PGE in diminishing the acute reaction to aspirin ingestion. The question of the potential use of any PGE analogue in the treatment of aspirin induced asthma remains unanswered. Studies with inhaled PGE or its analogue are now needed.

Misoprostol (Cytotec) was obtained from Searle. Placebo tablets were prepared by Biocom (Rzeszów, Poland).

1 Ham EA, Sodermann DD, Zanetti ME, et al. Inhibition by prostaglandins of leukotriene $\mathrm{B}_{4}$ release from activated neutrophils. Proc Natl Acad Sci USA 1989;80:4349-53.

2 Hogaboam CM, Bissonnette EY, Chin BC, et al. Prostaglandins inhibit inflammatory mediator release from rat mast cells. Gastroenterology 1993;104:122-9.

3 Kuehl FA, Dougherty HW, Ham EA. Interactions between prostaglandins and leukotrienes. Biochem Pharmacol 1984, 33:1-5.

4 Marone G, Kagey-Sobotka A, Lichtenstein LM. Effects of arachidonic acid and its metabolites on antigen-induced histamine release from human basophils in vitro. $f$ Immunol histamine release from

5 Raud J, Dahlén S-E, Sydbom A, et al. Enhancement of acute allergic inflammation by indomethacin is reversed by prostaglandin $\mathrm{E}_{2}$ : apparent correlation with in vivo modulation of mediator release. Proc Natl Acad Sci USA 1988;85:2315-9.

6 Tauber AJ. Immunologic release of histamine and slow reacting substance of anaphylaxis from human lung. Effect of prostaglandins on release of histamine. F Immunol 1973 111:27-32.

7 Gold KN, Weyand CM, Goronzy JJ. Modulation of helper T cell function by prostaglandins. Arthritis Rheum 1994;37: 925-33.

8 Haynes DR, Whitehouse MW, Vernon-Roberts B. The prostaglandin $\mathrm{E}_{1}$ analogue, misoprostol, regulates inflammatory cytokines and immune functions in vitro like natural prostaglandins $\mathrm{E}_{1}, \mathrm{E}_{2}$ and $\mathrm{E}_{3}$. Immunology 1992;76:251-7.

prostaglandins $\mathrm{E}_{1}, \mathrm{E}_{2}$ and $\mathrm{E}_{3}$. Immunology 1992;76:251-7.
Schäfer $\mathrm{D}$, Lindenthal U, Wagner M, et al. Effect of prostaglandin $\mathrm{E}_{2}$ on eicosanoid release by human bronchial biopsy specimens from normal and inflamed mucosa. Thobiopsy specimens from

10 Alam R, Dejarnatt A, Stafford S, et al. Selective inhibition of the cutaneous late but not immediate allergic response to antigens by misoprostol, a PGE analog. Am Rev Respir Di 1993;148:1066-70.

11 Rosetti RG, Brathwaite K, Zurier RB. Suppression of acute inflammation with liposome associated prostaglandin $\mathrm{E}_{1}$ Prostaglandins 1994;48:187-95.

12 Pavord ID, Tattersfield AE. Bronchoprotective role for endogenous prostaglandin E2. Lancet 1995;345:436-8.

13 Szczeklik A. Aspirin-induced asthma as a viral disease. Clin Allergy 1988:18:15-20.

14 Pavord ID, Wong CS, Williams J, et al. Effect of inhaled prostaglandin $\mathrm{E}_{2}$ on allergen-induced asthma. Am Rev Respir Dis 1993;148:87-90.

15 Vaghi A, DeBernardi G, Pieroni MG, et al. Time course of the protective effect of inhaled $\mathrm{PGE}_{2}$ against ultrasonically nebulized distilled water-induced bronchoconstriction. Eur Resp F 1996;9(Suppl 23):33S

16 Pavord ID, Wisniewski A, Mathur R, et al. Effect of inhaled prostaglandin $\mathrm{E}_{2}$ on bronchial reactivity to sodium metabisulphite and methacholine in patients with asthma. Thorax 1991;46:633-7.

17 Melillo E, Wooley KL, Manning PJ, et al. Effect of inhaled $\mathrm{PGE}_{2}$ on exercise-induced bronchoconstriction in asthmatic subjects. Am 7 Respir Crit Care Med 1994;149:113841 .

18 Szmidt M, Wasiak W. The influence of misoprostol (synthetic analogue of prostaglandin $\mathrm{E}_{1}$ ) on postaspirin (synthetic analogue of prostaglandin $\mathrm{E}_{1}$ ) on postaspirin
bronchoconstriction in aspirin sensitive asthmatics. F Invest Allergol Clin Immunol 1996;6:121-5.

19 Szczeklik A, Mastalerz L, Nicankowska E, et al. Protective and bronchodilator effects of prostaglandin E and salbutamol in aspirin-induced asthma. Am $\mathcal{F}$ Respir Crit Care Med 1996; 153:567-71.

20 Sestini P, Armetti L, Gambaro G, et al. Inhaled PGE prevents aspirin-induced bronchoconstriction and urinary $\mathrm{LTE}_{4}$ excretion in aspirin-sensitive asthma. Am $\mathcal{F}$ Respir Crit Care Med 1996;153:572-5.

21 Taniguchi M, Sakakibara H, Suetsugu S, et al. Subbioactive dose of PGE especially inhibits aspirin-induced attacks in (abstract). Aller 1996;51 (Suppl):84

22 Graham DY, Agrawal NM, Roth SH. Prevention of NSAID-induced gastric ulcer with misoprostol: multicentre, double-blind, placebo-controlled trial. Lancet 1988;ii: tre, double

23 Smallwood JI, Malavista SE. Misoprostol stimulates leukocyte cyclic adenosine 3',5'-monophosphate production and 
synergizes with colchicine: novel combination of established drugs may boost anti-inflammatory potential. $\mathcal{F}$ Pharmacol Exp Ther 1994;269:1196-204.

24 Wheeldon A, Vardey CJ. Characterization of the inhibitory prostanoid receptors on human neutrophils. Br F Pharmacol 1993;108:1051-4.

25 National Heart, Lung and Blood Institute, National Institutes of Health. Global strategy for asthma management and prevention. NHLBI/WHO Workshop Report. Publication No. 95-3659, 1995.

26 Phillips GD, Foord R, Holgate ST. Inhaled lysine-aspirin as a bronchoprovocation procedure in aspirin-sensitive
asthma: its repeatability, absence of late-phase reaction, and the role of histamine. $\mathcal{F}$ Allergy Clin Immunol 1989;84: 232-41.

27 Grzelewska-Rzymowska I, Ro¿niecki J, Szmidt M. Nadwracliwoœæ na aspirynê $\mathrm{i}$ inne niesteroidowe leki przeciwzaplne - metody ujawniania nadwra ¿liwoœci i wytwarzania stanu tolerancji. Pol Arch Med Wewn 1989;81:107-13.

28 Christie PE, Tagari P, Ford-Hutchinson AW, et al. Urinary leukotriene $\mathrm{E}_{4}$ after lysine-aspirin inhalation in asthmatic subjects. Am Rev Respir Dis 1992;146:1531-4.

29 Christie PE, Tagari P, Ford-Hutchinson AW, et al. Urinary leukotriene $\mathrm{E}_{4}$ concentrations increase after aspirin challenge in aspirin-sensitive asthmatic subjects. Am Rev Respir Dis 1991;143:1025-9. 